\title{
Los indios novohispanos en la evangelización: ¿imposición o adaptaciones?
}

\author{
José Luis DE RoJAS \\ Universidad Complutense de Madrid \\ phempo@ucm.es
}

Recibido: $19 / 11 / 2015$

Aceptado: 28/7/2016

\section{RESUMEN}

La evangelización de la Nueva España fue un asunto complejo y los indígenas tuvieron una parte activa que generalmente se deja de lado en las investigaciones. Nos proponemos presentar ejemplos de esta participación a través de los testimonios de los evangelizadores presentes en manuales de ministros, catecismos, confesionarios, etc.

Palabras clave: Evangelización, Nueva España, indígenas.

\section{Indians of New Spain in Front of the Evangelization: Imposition or Adaptations?}

\section{ABSTRACT}

The evangelization in New Spain was a complicate event and the indigenous people were active in the process, although their role has not been generally investigated. Our purpose is to show examples of this participation founded in the writings of evangelizadores: manuales de ministros, catechisms, confesionarios, etc.

Key words: Evangelization, New Spain, indigenous people.

Sumario: 1. Introducción. 2. Prácticas indígenas detectadas. 3. Algunas reflexiones. 4. Referencias bibliográficas.

\section{Introducción}

La mayoría de los testimonios sobre la evangelización de la Nueva España que nos han llegado procede de un mismo ámbito: el religioso. Por ello, la mayor parte de lo que cuentan tiene que ver con los evangelizadores y sus actuaciones, con los problemas que la empresa de la conversión les presentaba y con la forma en que trataron de resolverlos. Pocas veces, y casi siempre de pasada, se ocupan de los indígenas.

Si nos aproximamos al elenco de estudiosos de la evangelización, nos encontramos con una situación similar: la mayoría pertenece a la iglesia o es muy afín a ella, y estudian fundamentalmente la acción evangelizadora o una parte de ella, como ocurre con los estudiosos de las órdenes religiosas. De hecho, los cronistas tienden a magnificar el papel de la orden a la que pertenecen, disminuyendo o despreciando el de las demás. Recientemente Valpuesta (2008) ha reivindicado el papel del clero secular utilizando el argumento de que es menos conocido que el del clero regular por no haber tenido prácticamente cronistas.

Los indígenas raramente aparecen y más raramente se considera que tuvieran ningún tipo de iniciativa en este asunto, fuera de resistencias y rebeliones. Una excepción a este proceder es un artículo de Klor de Alva (1982) en el que planteaba diversas reacciones de los indígenas novohispanos ante la evangelización y en ellas incluía cuestiones de conciencia, comportamiento y apariencia, como veremos más adelante. 
Un factor que nunca deberíamos dejar de lado es la influencia del tiempo. La evangelización fue un proceso, ligado generalmente al de conquista. En cada momento y lugar comienza de nuevo y experimenta problemas similares a los descritos por los evangelizadores para los primeros años tras la conquista de México, cuando en la realidad vive momentos diferentes y simultáneos en cada lugar. No fue lo mismo implantar la nueva fe de primeras que adoctrinar a quienes nacían en un mundo en el que ya los frailes y los monasterios, los clérigos y las iglesias, eran parte de su vida diaria.

Volvamos a los comienzos. Tras la euforia inicial, con millones de bautizados, comenzaron los disgustos para los evangelizadores cuando aparecieron los problemas con los evangelizados. Se habían equivocado los misioneros en su apreciación, sin duda llevados por el entusiasmo, y los comentarios sobre esas situaciones que de repente percibieron nos sirven a nosotros de punto de partida para nuestras reflexiones:

«pero duró poco, porque ellos hicieron entender a los más de los religiosos, que toda la idolatría, con todas sus ceremonias y ritos, estaba ya tan olvidada y abominada que no había para que temer este recatamiento, pues que todos eran bautizados y siervos del verdadero Dios; y esto fue falsísimo, como después acá lo hemos visto muy claro, que ni aun ahora cesa de haber muchas heces de idolatría y de borrachería y de muchas malas costumbres, lo cual se hubiera mucho remediado si aquel negocio fuera adelante como se comenzó» (Sahagún 1975: 581 [lib. X]).

«La ocasión que han dado estos naturales para que siempre los ministros de la fe católica anden con ellas la barba sobre el hombro en las cosas de la idolatría fué porque a los principios, con no tener entendidas las cosas de la fe, ni aun copia de quien se la enseñase, ni haber visto milagros ningunos, se declararon por cristianos y que recibían a Nuestro Señor Jesucristo por su Dios, y que querían servirle y obedecerle como todos los otros cristianos. Pero el dejar todos los otros dioses, y creer muy de verdad que no eran dioses sino diablos, y dejar todas sus imágenes y cultura, renegando de ellos y de todas sus ceremonias, servicios y doctrinas, esto no lo hicieron, y de sobre pensado y platicado entre sí de no lo dejar en ningún tiempo, como se halló después asá [sic] haberlo hecho y determinado entre todos los sátrapas, señores y principales. Lo primero afirmaron con grande humildad y lágrimas delante de los predicadores del Evangelio, y de lo segundo no dijeron nada de lo que había pasado entre ellos, sino que preguntados si renegaban de sus dioses y de sus idolatrías \&c., a todo respondían que sí y con este catecismo se baptizaron y quedaron persuadidos los predicadores que entonces les predicaban que habían recibido la fe católica, y detestado y renegado de todos los ídolos y de toda la idolatría antigua con toda sinceridad y verdad, y así lo afirmaron y predicaron a todos los que después de ellos vinimos» (Sahagún 1981 [1583]: 381-382).

«El engaño de los frailes fue fruto de su descuido y de la sibilina actuación de los indígenas que hicieron creer que se habían convertido cuando en realidad no había sido así» (Sahagún 1981 [1583]: 382-383).

«estos tales son estos miserables indios idólatras, que son de tan gran ignorancia, y simplicidad, y tan fáciles a persuadirse en sus engaños, que les parece, que se puede conservar la ley de Dios, y los Mysterios de nuestra sancta fée con el conocimiento de sus antiguos y falsos Dioses: el Sol, la Luna, el fuego, las aguas, los animales terrestres y volátiles, las piedras y los árboles, dándoles crédito, y teniéndolos en su coraçon, y haziendo memoria de ellos en sus trabajos, y necesidades, y menesteres de la vida humana, porque como los misterios, que se les enseñan y predican, no los ven, ni tocan 
con las manos, porque han de obrar en esto, mediante la dirección de la Fée infusa, que recivieron en el santo Baptismo: y por otra parte ven estos viles, y materiales ídolos suyos, fácilmente se convierten á llamarlos, é invocarlos, pareciéndoles, que tienen más seguro el favor con el falso Dios, que ven, y tocan con las manos, que con el Dios verdadero, que adoran con la fée» (Serna 1900 [1656]: 277).

Sea uno o sea otro quien tenga razón, sean inocentes o culpables los indígenas en su no comprensión de lo que significaba ser cristiano, la realidad es que la religión antigua y la nueva siguieron coexistiendo, cuando no cohabitando. Muestra de ello es la presencia de los escritos sobre extirpación de idolatrías que se repiten en el siglo XVII: Pedro Ponce (1900), Pedro Sánchez de Aguilar (1900 [1613]), Hernando Ruiz de Alarcón (1900 [1629]), Gonzalo de Balsalobre (1900 [1656]) y Jacinto de la Serna (1900 [1656]).

Parte de nuestro problema es saber de verdad qué pensaban los indígenas. O mejor dicho qué pensaban los que lo hacían, pues la mayoría probablemente no se hacía ningún cuestionamiento sobre las creencias religiosas, sino que se limitaba a obedecer lo que sus superiores les mandaban. Y para muchos nobles indígenas su puesto «bien valía una misa» y estuvieron gustosos de colaborar en la implantación de la nueva religión. De hecho, Lockhart (1992: 204-205) asocia la resistencia política a la resistencia religiosa. Y los que no resistían procuraban que sus sujetos fueran buenos cristianos y vivieran en la ley de Jesucristo (Motolinía 1979: 94 [trat. II, cap. 5])

Como ya hemos comentado, Klor de Alva ha sido el único hasta ahora (que nosotros sepamos) que se ha propuesto profundizar en los sentimientos cristianos de los indígenas. Él mismo avisa que sus categorías ni siquiera son mutuamente excluyentes, pero en la variedad de comportamientos que presenta tuvo en cuenta una serie de variables como la creencia, el entendimiento, la participación en los ritos, incluyendo si era voluntaria o forzada, la resistencia al cristianismo y sus variantes y el mantenimiento de costumbres antiguas junto a las nuevas (Klor de Alva 1982: 351-352).

Tal y como avanzábamos, resulta muy difícil medir la creencia y el entendimiento, mientras que es más sencillo percibir la participación en los ritos. Lo externo es visible y lo interno no. Probablemente ayudaría el abordar en primer lugar el fenómeno de las creencias religiosas en profundidad. Por ejemplo, las reflexiones de Klor de Alva podrían aplicarse también a los indígenas prehispánicos y preguntarnos el grado de creencia, entendimiento y participación de los indígenas en su propia religión antigua. Y lo mismo podríamos hacer con los españoles del Viejo Mundo, lo que nos ayudaría a precisar qué problemas son particulares y cuáles son universales. Durante mucho tiempo habían convivido varias religiones en la península ibérica, así que deberíamos tener mucho campo que cubrir. Y algunas conclusiones se podrían sacar de las desventuras de Menocchio (Ginzburg 1981) y de las de los «cristianos de Alá» (Bennasar y Bennasar 1989), cuyo poco conocimiento de la doctrina cristiana les suponía un calvario cuando eran rescatados de manos de los musulmanes y las autoridades les interrogaban para comprobar si se habían mantenido firmes en la fe cristiana. La literatura nos ayuda un poco con novelas como San Manuel Bueno, Mártir, de Miguel de Unamuno, y mucho podemos aprender de la veleidad de los creyentes con casos como el de los cultos-cargo de la Polinesia (Worsley 1980). 


\section{Prácticas indígenas detectadas}

Un rastreo por las crónicas y textos religiosos antiguos y por las obras de autores modernos nos ha permitido aproximarnos al conocimiento de los asuntos que nos preocupan.

\subsection{Colaboración en la evangelización}

Olaechea (1969) habla de niños que ayudaban en las tareas de la evangelización y es algo que aparece reiteradamente en Mendieta (1945 [lib. III, cap. XVI]) y Motolinía, al que generalmente copia fray Gerónimo cuando trata de estos asuntos. Sahagún (1975: 581 [lib. X]) también se refiere a este proceder, incidiendo en que había muchachos indios espías que ayudaban a los frailes a detectar idolatrías encubiertas.

Motolinía (1979: 84 [trat. II, cap. 3]) dice que los indios acudían voluntariamente a recibir el bautismo y da cifras muy altas. Es posible que esta disponibilidad franciscana tenga que ver con que exigían mucho menos para bautizar que los dominicos, como señala Cline (1993: 458).

En los casos en los que podemos analizar los bautismos encontramos gran variabilidad, sin poder establecer una regla fija en el bautismo de los hijos de las parejas en que uno, los dos, o ninguno están bautizados. Esto ocurre en los Padrones de Morelos (ver Cline 1993: 459), aunque sí parece haber un predominio de bautismo entre las élites locales (Cline 1993: 460). En su cuadro 8, Cline (1993: 468) nos muestra la gran diversidad que había en el bautismo de los casados, llegando al caso de que aparezcan casados por la iglesia individuos que no habían sido bautizados. Claro que esto podría deberse a lo incompleto de la fuente, pues también se detecta que en muchos casos se diga que en una casa ninguno estaba bautizado y en el desglose de los habitantes se demuestre lo contrario (ver Cline 1993: 469; Rojas 2008).

También hay que señalar la insistencia con que algunos pueblos solicitaban tener fraile o clérigo (León-Portilla 1994: 163) y la edificación de iglesias:

«Cosa maravillosa fue el fervor y diligencia con que los indios de esta Nueva España (después que les fue predicada la palabra de Dios) procuraron edificar en todos sus pueblos iglesias, acudiendo hasta las mujeres y niños a acarrear los materiales, $\mathrm{y}$ aventajándose los unos con envidia de los otros en hacerlas mayores y mejores, y adornándolas según su posible, como en los capítulos precedentes se ha visto. Y si les dejasen, cada uno querría tener una iglesia junto a su casa. Y ya que esto no pueden, tienen todos ellos sus adoratorios a do rezan y se encomiendan a Dios. Y los que alcanzan caudal, parece que todo lo querrían emplear en cosas que causen memoria de Dios y de sus santos. Y así es cosa ordinaria remanecer de nuevo en cada convento de cuando en cuando imágenes que mandan hacer de los misterios de nuestra redención o figuras de santos en quien más devoción tienen; unos para sus casas, donde les hacen sus capillitas o retretes y les hacen sus andas para que se lleven en las procesiones. Y de estas apenas hay pueblo que tenga religiosos donde no hay cantidad de ellas. $Y$ en acabando de hacer estas imágenes, tráenlas a mostrar al guardián o prior del convento para que vea si están bien hechas y devotas, y se use de ellas con su aprobación» (Mendieta 1945, 3: 80 [lib. IV, cap. XVIII]). 
El uso de los niños, que ya hemos señalado, es un tema importante, pues se consideró que era la forma más fácil de implantar la nueva fe:

«Ansi mismo, porque el fruto más çierto y durable se esperava, como se vee, en los niños, y por quitar de rayz tan mala memoria, les tomamos todos los niños, hijos de caçiques y prinçipales por la mayor parte, quantos pudimos, para los criar e yndustriar en nuestros monesterios, y con ellos no poco trabajamos, enseñándoles a leer y a escrivir y cantar canto llano y de organo, y deçir las oras cantadas y ofiçiar las misas e ynponerlos en todas las buenas costumbres christianas y religiosas; por manera, que no solamente estos an sido traydos al camino de nuestra verdad y christiandad, mas ya ellos mismos, fechos maestros é predicadores de sus padres y mayores, discurren por la tierra decubriendo y distruyendoles sus ydolos y apartando los de sus viçios nefandos, y á vezes su vida corre peligro. Y con el favor de las varas que agora V.M. les a dado, los alguaziles, sus naturales, son lo que más persiguen los ritos y çerimonias gentíicas, y ellos nos son muy grande ayuda, mayormente contra los viejos que todavía están con sus ydolos y los asconden quanto pueden; avnque todavia se allegan bien á la dotrina y con harta deboçion á las yglesias y con muchas lagrimas á las confisiones, y se casan á ley y á bendiçion» (Valencia 1974 [1532]: 56).

«¿Qué diremos de los hijos de los naturales de esta tierra? Escriven, leen, cantan canto llano é de organo é contrapunto, hazen libros de canto, enseñan á otros, la musica é regozijo del canto eclesiastico en ellos está prinçipalmente, é predican al pueblo los sermones que les enseñamos, é dizenlo con muy buen spiritu; la frequençia de las confesiones con solloços e lagrimas, la confesion pura é simplicisima, la emienda junta á ella nos qui contarctavimus de verbo vitae lo sabemos...» (Testera 1974 [1533]: 65).

El problema de esta práctica fue que no siempre fueron los hijos de los caciques los que acudieron a los colegios, sino los de sus criados (Mendieta 1945, 2: 60 [lib. III, cap. XV]). Las consecuencias de esto se pusieron de manifiesto cuando los estudiantes volvieron a sus casas y los frailes trataron de favorecer sus candidaturas para ocupar los puestos políticos. Duverger (1990: 122) habla de estas prácticas y hay que preguntarse qué pasó cuando los frailes impusieron a sus pupilos en los cargos. Pero no siempre fue así, sino que en muchos casos acudieron realmente los hijos de los caciques a ser educados con los frailes. Casos contrastados son el de D. Pablo Nazareo (2000 [1561]: 238), quien se había criado con los franciscanos y se permitía el lujo de escribir a Felipe II en latín; y el del famoso cacique de Coyoacán D. Juan de Guzmán (2000 [1536]: 114), quien también habría sido criado por los franciscanos.

Las preferencias de los pueblos por una u otra orden quedan bien de manifiesto en la obra de Mendieta (1945 [lib. III, caps. LV-LX]), aunque con la esperada desviación de que casi siempre prefieren a los franciscanos. Caso sonado, con repercusiones que llegaron hasta la metrópoli, fue el de Teotihuacan en el que incluso tuvo que participar el oidor Alonso de Zorita (Mendieta 1945, 2: 208-215 [lib. III, cap. LIX]).

En el proceso a don Carlos Ometochtli, entre las acusaciones que él negó aparece la de que había dicho que la religión cambiaba según qué padres la predicaran:

«Preguntado, si asimismo decía este confesante que los frayles de Sant Francisco thenian una manera de vida y de vestido, dotrina y oración, y otra diferente los dominicos y otra los agustinos, y otra los clérigos, como era público...» (González Obregón 2009: 80). 
La aceptación de la existencia de esas diferencias nos obliga a reflexionar sobre esas preferencias y, más profundamente, sobre las dificultades de la evangelización.

Ricard (1986: 158-159) afirma que los indios favorecen a unas u otras órdenes religiosas. Duverger (1990: 221) va más lejos y cifra la posibilidad del éxito en la colaboración con los indígenas: «se tiene más bien la impresión de que los monjes, en su misión, se han beneficiado de cierta complicidad indígena».

Ya hemos mencionado el caso de Teotihuacan y otros testimonios de Mendieta. Para Amecameca, Chimalpahin (1965: 251-252) habla de fray Martín de Valencia y su estrecha relación con don Tomás de San Martín Quetzalmazatzin, quien incluso le alojaba. La otra facción política del pueblo estaba en tratos con los dominicos.

También los clérigos se involucraban en la política local y participaban en las elecciones, tomando partido (Haskett 1994: 306-307). No está claro si en estas relaciones podemos contemplar las de parentesco, pues con el tiempo algunas familias contaban en su seno con españoles, indios y mestizos, incluidos sacerdotes, como ocurrió con Teotihuacan y los Alva Cortés Ixtlilxochitl; e incluso los parentescos pueden aparecer en el caso de los curas que tenían amantes (ver Haskett 1994: 319 y ss.).

La dificultad de la tarea ya era grande por la escasez de evangelizadores, y así es señalada por Ragon (1992: 119) y acotada por Rubial (1989: 56-58) con dos por convento en promedio (Ricard 1986: 58); mientras que Fernández (1994: 171) dice que, en 1559, había en la Nueva España 210 dominicos. Así pues, la escasez de frailes determinaba que hubiera pocas visitas de los sujetos (Rubial 1989: 150-151) por lo que el control de la feligresía dejaba mucho que desear. Es importante a este respecto el testimonio de un arzobispo de México a mediados del siglo XVI:

«El estado desta Iglesia es desta manera, que en unas partes hay monasterios de dos o tres frailes y los más han sido hasta aquí de los que tienen asiento en un pueblo y de vesita a dos, cuatro, ocho, doce, quince y veinte leguas y treinta y más. El un fraile queda en el monasterio, el otro anda por las visitas que tiene que serán diez, quince y veinte pueblos cabeceras y más los sujetos, por manera que entre dos frailes sacerdotes en muchas partes tendrán a cargo más de cien mil ánimas: destos pueblos unos son vesitados de quince a veinte días otros a mes otros a dos y a cuatro y a seis meses y aún relación tenemos que en nuestro arzobispado hay pueblos donde en cinco años no ha habido fraile ni clérigo más de dos o tres veces que de paso que han pasado por allí algún sacerdote que bautizaba y casaba los que hallaba, y la visita ha sido tan de presa que comúnmente que llega sobre la tarde el religioso y dice misa y casa y bautiza los que halla y base» (Montúfar 1939 [1556]: 72).

Otro problema fue el de la lengua. En el convento de Charo-Matlatzinco sólo hubo tres priores en más de cien años, cuando debían cambiarse cada tres. No se pudo realizar el cambio por «la rareza de la lengua» (Rubial 1989: 118, 142). El esfuerzo lingüístico de los evangelizadores es bien conocido y, gracias a ellos, tenemos numerosos sermonarios, confesionarios, artes, etc. Pero no todo era predicar, había también que escuchar, sobre todo en las confesiones, en las que estaba descartada la participación de un intérprete. La evolución de las preguntas de los confesionarios puede responder a una presión de los indígenas, pero también a una mejora del conocimiento de los confesores que podían aventurarse a escuchar y comprender descripciones más largas y no limitarse a números o respuestas de «sí o no». 
En las disposiciones que se dictan se pueden encontrar a veces rastros de las prácticas de los indígenas y los esfuerzos que se hacían para corregirlos. Hanks (2010: 249) cuenta cómo en las disposiciones que se hicieron en maya en Yucatán se cambió la expresión «oir la misa» por «oir entera la misa», puesto que los indios tenían el hábito de marcharse antes de que terminara.

En los manuales para confesores se perciben influencias indígenas en las preguntas: número de dioses a los que adoraban, cobros excesivos de tributos o consumo de alucinógenos (Azoulai 1993). Ricard (1986: 210) dice que había indios que alegaban estar borrachos cuando pecaron para ser absueltos, lo cual está en contra de la tradición prehispánica y sí en consonancia con las nuevas normas cristianas. Serna (1900 [1656]: 388) afirma que los indios trataban de utilizar la confesión para librarse de la culpa, de manera similar a la costumbre prehispánica, con la ventaja de que no había límite de veces lo que les daba mucha mayor libertad de acción. Molina (1984 [1569]: 82r-84v) menciona en las preguntas sobre la gula la presencia de «honguillos», del ololiuhqui y la carne humana o el maíz cocido con ella. También aparecen diversas preguntas relacionadas con las actividades «pecaminosas» de los caciques y principales (Molina 1984 [1569]: 40v-44v). Andrés Lira (2006: 1056-1058) comenta la condición jurídica del pecado en Alonso de Molina y menciona también la aparición de la explotación de los macehuales por los principales.

Sobre la confesión y el perdón de los pecados se extiende Mendieta (1945, 2: 130-133 [lib. III, cap. XLI]) haciendo hincapié en el fervor con el que buscaban los indígenas las confesiones y cómo llegaban a acosar a los confesores para que les absolvieran. Veamos un último testimonio sobre este asunto:

«Cerca de lo arriba dicho sabemos que aún después acá, en el cristianismo porfían a llevarlo adelante, en cuanto toca a hacer penitencia y confesarse por los pecados graves y públicos, como son homicidio, adulterio, etc., pensando que, como en el tiempo pasado, por la confesión y penitencia que hacían se les perdonaban aquellos pecados en el foro judicial, también ahora, cuando alguno mata o adultera acógese a nuestras casas y monasterios, y callando lo que hicieron, dicen que quieren hacer penitencia; y cavan en la huerta y barren en casa, y hacen lo que les mandan y confiésanse de allí a algunos días, y entonces descarnan su pecado y la causa por que vinieron a hacer penitencia; acabada su confesión, demandan una cédula firmada del confesor, con propósito de mostrarla a los que rigen, gobernador y alcaldes, para que sepan que han hecho penitencia y confesándose y que ya no tiene nada contra ellos la Justicia.

Este embuste casi ninguno de los religiosos ni clérigos entienden por dónde va, por ignorar la costumbre antigua que tenían, según que arriba está escrito, más antes piensan que la cédula la demandan para mostrar cómo está confesado, aquel año. Esto sabemos por mucha experiencia que de ello tenemos» (Sahagún 1975: 38 [lib. I, cap. XII]).

$\mathrm{Y}$ es que debemos tener en cuenta el conocimiento de las leyes cristianas que los indígenas llegaron a tener y el «uso interesado de la justicia eclesiástica» (Zaballa 2010: 45) que llegaron a practicar. 


\subsection{Matrimonios}

Posiblemente este de los matrimonios fue uno de los mayores problemas en los primeros tiempos. Las diferencias entre las creencias indígenas y las cristianas eran tan notorias que necesariamente debieron surgir problemas. Y es que no solamente estaba en juego la parte religiosa, sino que la organización social estaba implicada completamente. Aunque fue la poligamia el tema más tratado, los grados de parentesco de los contrayentes eran una parte siempre presente pues en muchas comunidades el matrimonio preferencial era entre grados prohibidos por la Iglesia. Es importante destacar que tanto en los testimonios antiguos como en los trabajos modernos apenas se plantea la voluntad de la mujer y mucho menos el destino de los hijos. En los casos de paso de la poligamia a la monogamia no se trataba solamente de «quedarse con una esposa», sino de atender a las abandonadas y a su prole, con un problema jurídico añadido: hijos naturales, legítimos, ilegítimos... Algunos indígenas parecen haber comprendido muy bien el sistema y eligieron casarse con la madre del hijo que querían que les heredara prácticamente in articulo mortis. Además, entre tanto, habían mantenido a sus diferentes esposas con una pena menor por no ser casados. Entre fornicación y adulterio había una diferencia muy grande. Y este problema debió estar presente en la mente de los evangelizadores que en ocasiones harían la vista gorda «atendiendo a un bien mayor». Motolinía (1979: 99 [trat. II, cap. 7]) dice que los polígamos tenían que dar a las mujeres y a los hijos que dejaban «con que se alimenten y matrimonien las hijas». Y hay que tener presente también un problema «político»: no era tan fácil elegir, pues las esposas tenían rangos diferentes asociados a parientes poderosos. Un asunto en el que coincidieron los indígenas prehispánicos con los coloniales y los españoles fue en la importancia del matrimonio en las alianzas políticas. Aun así, la descripción de Ricard es muy interesante. En ella se describe cómo los indígenas utilizaban a los frailes para hacer y deshacer matrimonios y estos procuraban que nadie se quedara desparejado (Ricard 1986: 204-207).

Gran parte del Itinerario de fray Juan Focher está dedicado al análisis de la casuística de qué hacer con el matrimonio de los indios que se convierten y está claro que una parte importante del relato de Ricard está motivado por la lectura de Focher. Pero en el tratado de éste encontramos aún más indicios, como en el caso siguiente:

«Sobre esto mismo hay que advertir que no siendo necesario el padrino para la validez del bautismo, habiendo causa razonable y en atención a un bien mayor, puede suprimirse. Así se suprime justamente en estas regiones, para que no se multipliquen los impedimentos matrimoniales entre estos Indios. Además, para que de aquí no tomen algunos de ellos ocasión de disolver sus matrimonios, diciendo con engaño que entre ellos existe un parentesco espiritual, en comprobación de lo cual hallarán ordinariamente testigos con facilidad; los cuales asegurarán que, en efecto, existía ya entre los mismos dicho parentesco, en cuyo caso habría que llegar al divorcio, ya que según testimonio del Panormitano en c. finali, de puragtione canonica, en ninguna parte se lee que el Papa haya dispensado en este parentesco.

Añádese a esto que con motivo de este parentesco muchos Indios de estas tierras difícilmente encontrarían con quien contraer matrimonio. Hallaríanse, en efecto, todos los habitantes de un pueblo ligados entre sí por algún parentesco bien carnal, o espiritual, 
bien por afinidad. Ordinariamente estos Indios no se casan sino con los de su pueblo, y aún no se les permite a los súbditos de un señor contraer con los de otro, para así no perder vasallos; a causa, pues, de este parentesco, sin que hubiera ningún otro impedimento, les resultaría a muchos difícil el contraer, por lo que tendrían que quedarse solteros, sin casarse» (Focher 1960: 65-67).

Queda clara la «culpabilidad» de los indios y también el conocimiento que tenían de las normas de la Iglesia y su capacidad de adaptación de las mismas en su propio beneficio. Para nosotros queda la duda de si efectivamente se llevó a cabo esa norma y en caso afirmativo durante cuánto tiempo. No es solamente un prurito de exactitud, sino que la variable tiene dependientes: por ejemplo, el compadrazgo entre los indígenas, muy importante en el siglo XX.

Caminos como el recorrido por Figueras (2003) analizando las mujeres bígamas de la Nueva España pueden ser muy gratificantes. Estrella Figueras encontró mujeres de todo tipo y condición con argumentos muy variados para justificar su proceder. Muchos de ellos tienen que ver con su nivel de comprensión de las normas cristianas, pero en otros, éstas se cruzaban con ideas populares sobre la moral y el qué dirán. Es posible que una investigación similar sobre los hombres nos ilustrara sobre su nivel de comprensión de la fe cristiana y su voluntad de practicarla.

\subsection{Engaños}

Una cita anterior de Sahagún y esta de Focher nos llevan a un punto donde la intencionalidad de los indígenas es manifiesta: engañar a los religiosos. Y no hay que limitarse a la anécdota de que no les decían la verdad para no enfadarlos, pues en realidad en muchos casos los padres caían bien a los indígenas, sino a otras prácticas que tienen más que ver con la postura de Sahagún en las citas que ya vimos. Un ejemplo temprano es la celebración de la fiesta del Corpus Christi en Tlaxcala en 1538, que coincidió con una gran celebración indígena (Motolinía 1979: 61 y ss. [trat. I, cap. 15]; Rojas 1983). «Idolatría envuelta en hipocresía» decía Serna (1900 [1656]: 449). A veces era la presión de los evangelizadores la que provocaba el engaño, como ocurría con la persecución de idolatrías. Motolinía (1979: 201 [trat. III, cap. 20]) dice que, ante la continua presión sobre la existencia de ídolos ocultos y la necesidad de descubrirlos, había indios que los fabricaban para entregarlos a los evangelizadores y que así les dejaran en paz. Esto se puede relacionar con Clendinnen (1987: 166 y ss.) cuando habla de las confesiones obtenidas bajo tortura cuando se perseguían los sacrificios humanos y cómo para eludir el castigo los indígenas inventaron todo lo necesario para contentar a los encuestadores. Es jocosa la forma en que se originó esto: al devolver a los torturados a la misma celda en que esperaban los siguientes, estos pudieron de esa forma ser informados de qué era lo que buscaban los inquisidores y con qué se contentaban. Así, descendió el grado de sufrimiento y creció de manera desmesurada el de sacrificados, tanto que se descubrió el pastel.

Algunas prácticas antiguas continuaron, como el baño en el temazcal, cuya promiscuidad preocupó mucho a los evangelizadores:

«Ya creo todo esto está muy olvidado, pero para encarecer la fe que estos naturales tenían en aquel agüero de bañarse indios e indias todos juntos, quiero contar lo que me 
aconteció en cierto pueblo, donde había esta usanza y mala costumbre, que instando y porfiando en la predicación y fuera de ella, en que los indios se bañasen por sí y ellas por sí, y poniendo rigor en ello y prometiendo castigo, usaron de un disimulo muy donoso y fue que ellas, cuando se bañaban, por no quebrantar su agüero y superstición, metían un niño, o dos consigo, de sus hijuelos, y ellos, una niña, o dos, de sus hijuelas, por disimulo, para que, si los apremiasen, responder que eran sus hijos y que los metían consigo, como en realidad de verdad lo respondieron, y no era que se acordasen de aquella abusión antigua» (Durán 1967a [1570]: 176 [cap. XIX]).

En la imposición de los nombres también hubo problemas, manteniéndose en muchos casos un nombre indígena al que se sumaba el nombre castellano. Esto se aprecia muy bien en los Padrones de Morelos, ya mencionados, y en la Matrícula de Huexotzinco, y era conocido por los frailes:

«Y porque ya hemos propuesto de dar aviso a los ministros, no dejamos nada por avisar. Sepan los reverendos padres que, juntamente con el nombre cristiano, se pone el nombre del signo en que nació antiguo, y lo tienen por renombre. Ejemplo: Si nació en el signo de la «culebra» y en el bautismo se puso Pedro, llámase Pedro Coatl, que es el nombre del signo en que nació, y si nació en el signo de la «lagartija», llámase Juan Cuetzpal, juntando el un nombre con el otro, y ansí de todos los demás. Dios nuestro señor alumbre a los ministros para contra tan mal enemigo y adversario, como es el demonio, y nos dé claridad en todas las supersticiones para destruirlas, y para entender esta ensalada y mezcla que de sus antiguas supersticiones y de la ley y cerimonias divinas tienen hecha» (Durán 1967b [1579]: 236 [cap. III]).

\section{Algunas reflexiones}

La búsqueda de evidencias de la voluntariedad indígena en la conquista no ha dado mucho resultado y queda la duda de si no se produjeron más casos o si no los hemos encontrado por la condición de nuestras fuentes, ya reseñada al principio. En otros ámbitos de las sociedades indígenas novohispanas cuantas más preguntas nos hacemos más evidente es la actividad de los indígenas, en muchos casos voluntaria y deliberada. Y como bien señaló Sahagún cuando mencionó la necesidad de quitar las costumbres indígenas por estar asociadas a las prácticas idolátricas, más asociación entre la vida diaria y la religión encontramos en el mundo colonial. Todo el ritmo de vida y sus conmemoraciones se vieron afectadas por la Iglesia: la construcción de monasterios e iglesias, la adscripción de santos patronos a los pueblos y la celebración de sus fiestas, la fundación de cofradías y su gestión, la organización social regulada por las nuevas normas de parentesco e incluso los tributos, en los cuales tantos ejemplos de manipulación indígena se han ido encontrando. Pues bien, cuando las normas de tributación gravaron a los casados, los indígenas retrasaron la edad del matrimonio (Ragon 1992: 119). Cuando el tributo se imponía a los jefes de las casas, los hijos casados no se emancipaban, como ocurría en Morelos.

Duverger (1990: 197) dice que hay influencia de las costumbres y deseos indígenas en la arquitectura franciscana, pero no precisa cuáles. Nosotros pensamos que la preferencia por unas y otras órdenes, como ocurrió en Teotihuacan, pueden llevar 
asociado lo que costaban unos y otros. Entre las iglesias franciscanas y las agustinas la diferencia es enorme, por ejemplo. Y sin dejar este tema siempre nos hemos preguntado por la razón de la existencia de tantas capillas abiertas en México, y dadas las pruebas del conocimiento que los indios tenían el derecho de «acogerse a sagrado» ${ }^{1}$, nos planteamos si no es esta una de las razones, por no considerarse el atrio parte de la iglesia y no gozar de los mismos privilegios.

Habría que revisar también la presencia cristiana en los testamentos, que es manifiesta, no sólo en el formato de los mismos, sino en el cumplimiento de las mandas, en las órdenes de enterramiento, en la cantidad de misas encargadas, en la presencia de confesores con nombre y apellido, en los sacerdotes que son albaceas y herederos y en mandas voluntarias para comprar imágenes o vestirlas, para dotar a iglesias de campanas, para terminar con la fundación de capellanías.

Hay que seguir buscando y abordar de otra manera la instalación del cristianismo entre los indígenas, no solamente entre los novohispanos, sino también en otras regiones de América.

\section{Referencias bibliográficas}

Azoulai, Martine

1993 Les péchés du Nouveau Monde. Les manuels pour la confession des indiens XVIXVII siècle. París: Albin Michel.

BaLsalobre, Gonzalo de

1900 «Relación auténtica de las idolatrías, supersticiones, varias observaciones de los indios del obispado de Oaxaca» [1656]. Anales del Museo Nacional de México 6: 227-260.

BENNASSAR, Bartolomé y Lucile BenNassar

1989 Los cristianos de Alá. La fascinante aventura de los renegados. Madrid: Nerea.

Chimalpahin Cuauhtlehuanitzin, Francisco de San Antón Muñón

1965 Relaciones originales de Chalco Amaquemecan, edición de S. Rendón, prefacio de Angel Garibay K. México: Fondo de Cultura Económica.

Clendinnen, Inga

1987 Ambivalent Conquests. Maya and Spaniards in Yucatan, 1517-1570. Cambridge: Cambridge University Press.

Cline, Sarah L.

1993 The Book of Tributes. Early Sixteenth-Century Nahuatl Censuses from Morelos. Los Angeles: University of California Press.

DuRÁN, Fray Diego

1967a «Libro de los ritos y ceremonias en las fiestas de los dioses y celebración de ellas» [1570], en Historia de las Indias de Nueva España e islas de Tierra Firme, ed. de Ángel $\mathrm{M}^{\mathrm{a}}$ Garibay, vol. 1, pp. 1-210. México: Editorial Porrúa.

\footnotetext{
1 Una evidencia de este conocimiento nos la proporciona Haskett (1987) cuando relata que don Antonio de Hinojosa, en cuanto empezaron sus dificultades con el alcalde mayor de Cuernavaca, se refugió en el convento y ya no salió más de él.
} 
1967b «El calendario antiguo» [1579], en Historia de las Indias de Nueva España e islas de Tierra Firme, ed. de Ángel Ma Garibay, vol. 1, pp. 211-330. México: Editorial Porrúa.

Duverger, Christian

1990 La conversión de los indios de Nueva España. Quito: Ediciones Abya Yala.

FERNÁNDEZ RoDríguez, Pedro

1994 Los dominicos en la primera evangelización de México (1526-1550). Salamanca: Editorial San Esteban.

Figueras VALLÉs, Estrella

2003 Pervirtiendo el orden del santo matrimonio. Bígamas en México, siglos XVI y XVII. Barcelona: Universitat de Barcelona.

FOCHER, Fray Juan

1960 Itinerario del misionero en América [1574]. Madrid: Librería General Victoriano Suárez.

GinzBurg, Carlo

1981 El queso y los gusanos. El cosmos según un molinero del siglo XVI. Barcelona: Muchnik.

GonZÁLEZ OBREGón, Luis

2009 Proceso inquisitorial del cacique de Tetzcoco [1910]. México: 53 ICA y Gobierno de la Ciudad de México.

GuzMán, Juan de

2000 «Información de don ... Itztolinqui, en español, Coyoacan 1536» [1536], en La nobleza indígena del centro de México después de la Conquista, Emma Pérez Rocha y Rafael Tena, eds., pp. 103-122. México: Instituto Nacional de Antropología e Historia.

HANKs, William F.

2010 Converting Words. Maya in the Age of the Cross. Berkeley: University of California Press.

HASKETT, Robert S.

1987 «Antonio de Hinojosa: un político pueblerino», en Lucha por la supervivencia en la América Colonial, David G. Sweet y Gary B. Nash, eds., pp. 285-332. México: Fondo de Cultura Económica.

1994 «Not a Pastor, but a Wolf: Indigenous-Clergy Relations in Early Cuernavaca and Taxco». The Americas 50 (3): 293-336.

KLOR DE Alva, Jorge

1982 «Spiritual Conflict and Accommodation in New Spain: Toward a Typology of Aztec Responses to Christianity», en The Inca and Aztec States 1400-1800. Anthropology and History, George A. Collier, Renato I. Rosaldo y John D. Wirth, eds., pp. 345-366. Nueva York: Academic Press.

León-PortiLla, Miguel

1994 «Un cura que no viene y otro al que le gusta la india Francisca». Estudios de Cultura Náhuatl 24: 139-170.

LIRA, Andrés

2006 «Dimensión jurídica de la conciencia. Pecadores y pecados en tres confesionarios de la Nueva España 1545-1732». Historia Mexicana 55 (4): 1139-1178. 
LOCKHART, James

1992 The Nahuas after the Conquest. A Social and Cultural History of the Indians of Central Mexico, Sixteenth Century through Eighteenth Centuries. Stanford: Stanford University Press.

Mendieta, Fray Gerónimo

1945 Historia eclesiástica indiana, 4 vols. México: Ed. Salvador Chávez Hayhoe.

Molina, Fray Alonso de

1984 Confesionario mayor en lengua mexicana y castellana [1569], edición facsimilar. México: Instituto de Investigaciones Históricas, Universidad Nacional Autónoma de México.

MontúFar, Fray Alonso de

1939 «Carta al Consejo de Indias. RAHM Muñoz 70: 12r-33v» [1556], en Epistolario de la Nueva España, vol. 8, pp. 70-96. México: Antigua Librería Robredo.

Motolinía, Fray Toribio de Benavente

1979 Historia de los indios de Nueva España. México: Editorial Porrúa.

NAZAREO, Pablo

2000 «Carta de don ... a la reina Isabel, en latín, México 12 de febrero de 1561» [1561], en La nobleza indígena del centro de México después de la Conquista, Emma Pérez-Rocha y Rafael Tena, pp. 235-243. México: Instituto Nacional de Antropología e Historia.

OlaecheA, Juan Bautista

1969 «Participación de los indios en la tarea evangélica». Missionalia Hispanica 77: 241-256.

Ponce, Pedro

1900 «Breve relación de los dioses y ritos de la gentilidad» [comienzos del siglo XVII]. Anales del Museo Nacional de México 6: 5-11.

RAGON, Pierre

1992 Les indiens de la découverte. Evangélisation, mariage et sexualité. Mexique, XVIe siècle. París: L'Harmattan.

RICARD, Robert

1986 La conquista espiritual de la Nueva España [1932]. México: Fondo de Cultura Económica.

RoJAs, José Luis de

1983 Calendarios mesoamericanos. Madrid: Universidad Complutense de Madrid.

2008 «Padrones de Morelos: impresiones sobre familias, tierras y tributos». Ponencia presentada en el Colloque International: Échanges et constructions culturelles dans les mondes ibériques. IRIEC-Université de Toulouse Le Mirail, Toulouse 13-15 de noviembre de 2008.

RuBIAL, Antonio

1989 El convento agustino y la sociedad novohispana (1533-1630). México: Instituto de Investigaciones Históricas, Universidad Nacional Autónoma de México.

Ruiz de Alarcón, Hernando

1900 «Tratado de las supersticiones y costumbres gentílicas que oy viven entre los indios naturales desta Nueva España» [1629]. Anales del Museo Nacional de México 6: 123-223. 
SAHAGún, Fray Bernardino

1975 Historia general de las cosas de la Nueva España. México: Editorial Porrúa.

1981 «Al lector (advertencia después del calendario)» [1583], en Bibliografía mexicana del siglo XVI, Joaquín García Icazbalceta, ed., pp. 380-382. México: Fondo de Cultura Económica.

SÁNCHEZ de Aguilar, Pedro

1900 «Contra idolorum cultores» [1613]. Anales del Museo Nacional de México 6: 13122.

SERnA, Jacinto de la

1900 «Manual de ministros de indios para el conocimiento de sus idolatrías y extirpación de ellas» [1656]. Anales del Museo Nacional de México 6: 261-475.

Testera, Fray Jacobo de

1974 «Carta de ... y otros religiosos al Emperador» [1533]. Cartas de Indias, tomo 1, pp. 62-66. Biblioteca de Autores Españoles 264. Madrid: Atlas.

VAlEnCia, Fray Martín de

1974 «Carta de ... y otros religiosos al Emperador» [1532]. Cartas de Indias, tomo 1, pp. 54-61. Biblioteca de Autores Españoles 264. Madrid: Atlas.

VALPUeSta Abajo, Nazario

2008 El clero secular en la América hispana del siglo XVI. Madrid: Biblioteca de Autores Cristianos.

WORSLEY, Peter

1980 Al son de la trompeta final. México: Siglo XXI Editores.

ZABALla, Ana de

2010 «Del viejo al nuevo mundo: novedades jurisdiccionales en los tribunales eclesiásticos ordinarios en Nueva España», en Los indios ante los foros de justicia religiosa en la Hispanoamérica virreinal, Jorge Traslosheros y Ana de Zaballa, coords., pp. 17-46. México: Instituto de Investigaciones Históricas, Universidad Nacional Autónoma de México. 